Acta Theriologica 38 (1): 31 - 38, 1993.

PL ISSN 0001 - 7051

\title{
Dispersal in Bank voles: benefits to emigrants or to residents?
}

\author{
Joanna GLIWICZ
}

\begin{abstract}
Gliwicz J. 1993. Dispersal in Bank voles: benefits to emigrants or to residents. Acta theriol. 38: $31-38$.

The paper revises the recent hypotheses on the evolution of dispersal behaviour in voles, namely Emigrant Fitness Hypothesis (EFH) versus Resident Fitness Hypothesis (RFH), on the basis of 3-year study on dispersal of Bank voles Clethrionomys glareolus (Schreber, 1780). The studied populations lived in three types of habitats: a small island, a rich alder forest (both optimal habitats) and small patches of woods (suboptimal habitat). The island population was treated as a control for dispersal occuring in two other populations. Young voles born in the first litters of the year commonly dispersed from the optimal natal habitat into the vacant suboptimal habitat. These immigrants had higher reproductive success in the new habitat than their counterparts in the control habitat. Residents, which were parents and younger siblings of emigrants, also benefitted from the absence of dispersers: their home ranges were less crowded and food depleted, and the rates of maturation were higher than in the control habitat. The gain in the inclusive fitness of matrilines with dispersing young is postulated as a ultimate cause for dispersal. A mutual overlap in predictions of $\mathrm{EFH}$ and $\mathrm{RFH}$ is indicated.
\end{abstract}

Agricultural University of Warsaw, Department of Wildlife Management, Rakowiecka 26/30, 02-528 Warsaw, Poland

Key words: Clethrionomys glareolus, dispersal behaviour, patchy environment, reproductive success

\section{Introduction}

Dispersal in small rodents is a somewhat specific phenomenon, resulting from the particular life history of these mammals. They commonly mature and reproduce in the year of their birth, but in order to do so, young of the year have to find vacant space for their breeding territories and home ranges in the middle of the breeding season. For this, they compete with their parent generation which is already established in the local habitat since the begining of the breeding season, or they find a new habitat, less crowded with older individuals.

Although dispersal in small rodents, and especially in voles, has been much studied and discussed (Lidicker 1975, Tamarin 1978, Gaines and McClenaghan 1980, Stenseth 1983, Gliwicz 1986, 1988a, b, Stenseth and Lidicker 1992), it is still not clear, which individuals disperse and which stay in their natal habitats, neither what are the proximate and ultimate factors causing dispersal. 
Recently, dispersal is most often viewed (by authors cited above) as a behaviour which brings gain in fitness to dispersers. Yet, this view is not shared by all students of dispersal. Anderson (1989) opposed this hypothesis, which he named the Emigrant Fitness Hypothesis (EFH) in favour of his own Resident Fitness Hypothesis (RFH). According to him, dispersers can only lose by leaving familiar natal habitats, and the ones who gain from their emigration are residents (Table 1).

Table 1. Emigrant Fitness Hypothesis (EFH) versus Resident Fitness Hypothesis (RFH), according to Anderson (1989).

\begin{tabular}{ll}
\hline EFH & - Emigration evolved through a gain in fitness to emigrants, \\
& - Dispersal is controled by genes of emigrants. \\
RFH & - Residents (parents) maximize fitness by manipulating their offspring into dispersal, \\
& - Dispersal is controled by resident behaviour.
\end{tabular}

My study on dispersal of Clethrionomys glareolus (Schreber, 1780) had been designed before Anderson's book was published, so it was not aimed at discriminating between the EFH and RFH. Yet, the purpose of my study was to look for possible benefits to both emigrants and residents of the Bank vole (Gliwicz 1989, 1990a, b, 1992).

\section{Characteristics of habitats and populations studied}

The study area was located in a heterogeneous, patchy landscape of NorthEastern Poland. It consisted of three types of habitats differing in their suitability to the Bank vole (optimal and suboptimal patches), and in their "openess" to dispersers (confined and open patches). A forest plot ( $0.7 \mathrm{ha}$ in area) located in a large, rich forest was the optimal-open habitat; two small woodlots ( $0.7 \mathrm{ha})$ surrounded by vast pastures were suboptimal habitats open to dispersers; a small island $(0.5 \mathrm{ha})$ in a lake was the optimal habitat (very similar to the forest plot) precluding dispersal (Table 2). All habitats under study were located within 3-km distance of each other.

Table 2. Characteristics of the studied habitats, indicating their suitability for the Bank vole and possibility of dispersal.

\begin{tabular}{lcc}
\hline \multirow{2}{*}{ Dispersal } & \multicolumn{2}{c}{ Habitat } \\
\cline { 2 - 3 } Possible & Optimal & Suboptimal \\
Precluded & Turtul Island & Woodlots \\
\hline
\end{tabular}


Operational definitions of optimal and suboptimal habitats adopted here are as follows: the optimal habitat provides suitable living conditions for the species all year round, whereas the suboptimal one is suitable only for some part of a year. Data on population density, age composition, age at maturity, home range characteristics and trappability of individuals were collected in the three habitats during three breeding seasons. The movements of animals between local habitats were not observed directly, but could be deduced from the comparison between habitats. The island was treated as a control for the open optimal habitat (forest plot), as it provided similar habitat conditions for the Bank vole but precluded emigration.

The differences between population density in optimal and suboptimal habitats were most pronounced in late April. Both optimal habitats were densely populated with overwintered individuals. All females were pregnant with first litters. Females' breeding territories were loosely distributed all over the available space, and little place was left for breeding territories of the next generation. In the suboptimal habitat, on he other hand, none or very few individuals occurred. This habitat was unattractive at that time of the year. Its herb layer - generally impoverished and highly seasonal as an effect of the neighbourhood of agricultural areas - was very sparce in the spring. Therefore, overwintered rodents, establishing breeding home ranges in April, avoided this habitat.

Young of the first litters $\left(\mathrm{Y}_{1}\right)$ born and weaned several weeks later (May/June) differed greatly in their distribution among the habitats. On the island, where all young remained in the isolated habitat, 2.3 young per overwintered female were recruited into the trappable population. On the forest plot, however, five time fewer young per female were found. Yet, the similarity of the two habitats (density of the population, proportion of pregnant females, food and cover conditions) suggested that the numbers of young born and weaned had been equal in both habitats. So, what happened to the young in the open optimal habitat? They left their natal population and dispersed into suboptimal habitats, empty at that time. In the suboptimal woodlots I found many $\mathrm{Y}_{1}$ young (Fig. 1), which could not have been born their, simply because their parent generation was absent from this habitat.

In July, young of the second litters of the year $\left(\mathrm{Y}_{2}\right)$ were recruited into the trappable population, and between-habitat comparison indicated that they remained in the habitats in which they were born (Fig. 1). It is important to note that in the suboptimal habitat living conditions for rodents in June-July were much better than before due to temporal development of a rich herb layer at the peak of the vegetation season. The habitat for a short time provided adequate food and shelter for voles (Gliwicz 1989).

Young born later in the season (from July to September $-\mathrm{Y}_{3,4}$ ) also remained in the natal habitats (Fig. 1) till the end of the breeding season. They, however, were not capable of maturing in the year of birth, and will not be further analised in this paper. 


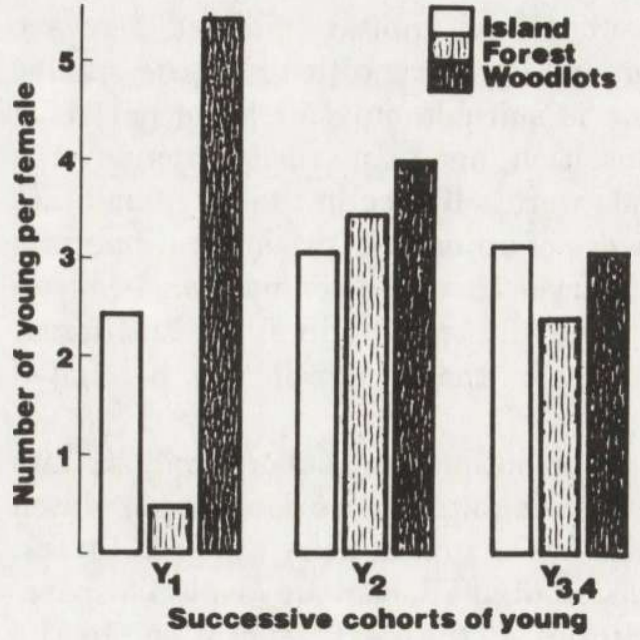

Fig. 1. Number of young of different cohorts $\left(Y_{1}\right.$, $\mathrm{Y}_{2}$ and $\left.\mathrm{Y}_{3,4}\right)$ 1-2 months old per breeding female, present in the three habitats (after Gliwicz 1989, modified).

The results presented in this chapter indicate that:

(1) the most common dispersers in the Bank vole are young born early in the spring as first litters of the year $\left(\mathrm{Y}_{1}\right)$,

(2) they disperse from optimal (donor) habitats, densely populated by overwintered animals, into vacant suboptimal (recipient) habitats,

(3) individuals born later in the season $\left(\mathrm{Y}_{2}\right.$ and $\left.\mathrm{Y}_{3,4}\right)$ do not emigrate from their natal habitats.

\section{Benefits to emigrants}

It was found that $\mathrm{Y}_{1}$ dispersers had a much higher chance to mature in the year of birth in a new habitat than their counterparts confined to the natal optimal habitat. Probability of maturation was the lowest for the island $Y_{1}$ inhabitants (Fig. 2). It can be assumed that if $\mathrm{Y}_{1}$ young born in the forest stayed there, their chances of sexually maturing would be as low as for the island young. But as only $22 \%$ of $\mathrm{Y}_{1}$ that had been born and weaned in the forest remained there, all of them matured. $\mathrm{Y}_{1}$ young that settled in the suboptimal habitat also had a very high chance of maturing in the same season.

Characteristics (size and overlap) of mature female home ranges in the three types of habitats in July (peak of the breeding season) indicated that the reason for suppressed maturation of $\mathrm{Y}_{1}$ females in the insular habitat was unavailability of vacant space for their breeding territories (Gliwicz 1989). Therefore, it may be stated that $\mathrm{Y}_{1}$ can gain much from their successful immigration into a vacant habitat. They are potentially capable of producing up to 3 litters in the current season, and young of the first of these litters are themselves able to give birth to one litter before the season ends. If $\mathrm{Y}_{1}$ had stayed in the natal optimal habitat, only about one third of them could mature and breed (Gliwicz 1990b). 
Fig. 2. Percentage of young males $(M)$ and females $(F)$ of different cohorts $\left(Y_{1}, Y_{2}, Y_{3,4}\right)$ maturing in the year of birth in the three habitats (after Gliwicz, 1989, modified). * - only $22 \%$ of $\mathrm{Y}_{1}$ young remained in the forest, all of them were mature.

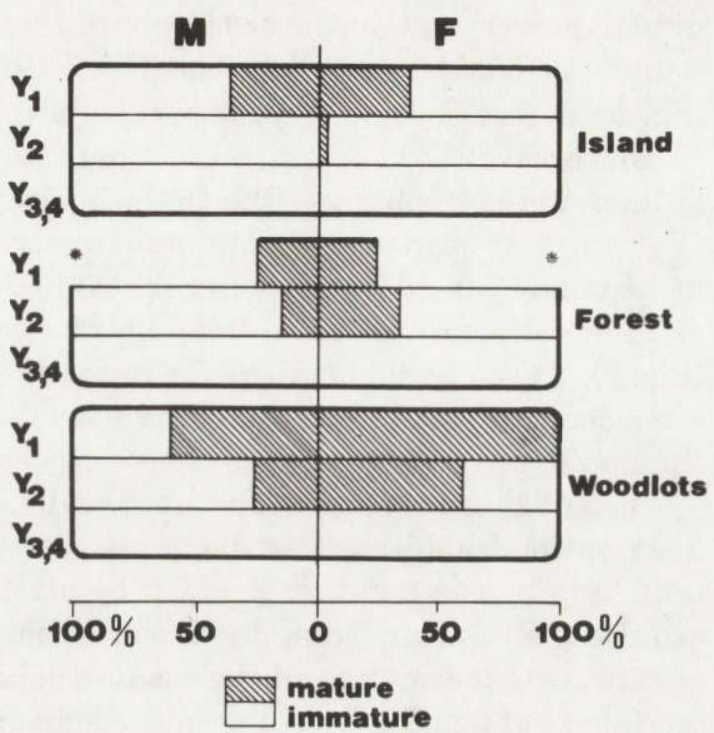

Moreover, once the young of the year become mature, their reproductive success (measured as a number of pregnancies per individual female, and number of litters sired by an individual male) is not habitat-dependent, being equal in the optimal and suboptimal habitats. Hence, since for the majority of voles reproduction in the year of birth is the only chance for leaving any offspring (due to high winter mortality) and since in optimal crowded habitats the maturation of $\mathrm{Y}_{1}$ young is suppressed, emigration from natal optimal habitats, and settlement and breeding in suboptimal ones seems to be a viable option for these individuals (Gliwicz 1990a).

Timing of the dispersal of $\mathrm{Y}_{1}$ individuals - the second month of the breeding season - gives these dispersers the best chance to find suitable vacant habitats because (1) the overall density of rodents is still low, and (2) many habitats which were unattractive in the spring became suitable for Bank voles due to the seasonal increase in plant biomass.

However, there are no data available for estimating how successful the dispersers are in getting into vacant habitats. In many studies of rodent populations no balance between numbers of emigrants and immigrants was found (for review, see Cockburn 1988) This suggests high mortality of dispersers on the way to new habitats. As long as the mortality remains unknown, gains in fitness to emigrants cannot be assessed.

\section{Benefits to residents}

Residents analyzed in this study were mothers and younger siblings $\left(\mathrm{Y}_{2}\right)$ of $\mathrm{Y}_{1}$ individuals. Although the relatedness between individuals was not estimated 
directly, a very low turnover of overwintered females in both optimal habitats (75 - $100 \%$ of females breeding from April till mid-July were the same individuals) indicated that $\mathrm{Y}_{1}$ and $\mathrm{Y}_{2}$ young were born to the same mothers.

Dispersal of $Y_{1}$ young increases chances of maturation and reproductive success of their younger siblings. Due to the emigration of the first born, the second born $\left(\mathrm{Y}_{2}\right)$ which are capable of gaining maturity in the current year, do so and produce at least one litter. It was found that $33 \%$ (versus $6 \%$ in the confined population) of $\mathrm{Y}_{2}$ females born in the optimal habitat became reproductive when $\mathrm{Y}_{1}$ dispersed (Fig. 2). $Y_{2}$ young did not disperse from the optimal open habitat, probably because after departure of $\mathrm{Y}_{1}$ and increased mortality of the overwintered generation from the end of July, they could find enough space to settle and breed in situ.

Dispersal of $\mathrm{Y}_{1}$ young also improves living conditions for their mothers. In the open optimal habitat after dispersal of $\mathrm{Y}_{1}$, territories of breeding females were used only by the territory holders, by males and a few $\mathrm{Y}_{2}$ females which did not acquire their own breeding territories. Therefore, crowding of their territories was significantly lower than in the insular habitat (Table 3 ). The least crowded were territories of females breeding in the suboptimal habitat, where space was always available.

Table 3. Crowding in the territories of mature females and their trappability in July, at the peak of the breeding season. Crowding measured as a number of individuals caught in a female territory. Trappability measured as a number of visits in traps per 20 trapping occasions. Mean values sharing the same superscript letter are significantly different ( $t$-Student test, $p<0.05$ ).

\begin{tabular}{lcc}
\hline Habitat & $\begin{array}{c}\text { Crowding } \\
\bar{x} \pm \mathrm{SD}\end{array}$ & $\begin{array}{c}\text { Trappability } \\
\bar{x} \pm \mathrm{SD}\end{array}$ \\
\hline Island & $10.3 \pm 3.8^{\mathrm{a}}$ & $13.4 \pm 8.7^{\mathrm{c}}$ \\
Forest & $7.2 \pm 2.7^{\mathrm{ab}}$ & $7.6 \pm 6.2^{\text {ed }}$ \\
Woodlots & $3.7 \pm 2.2^{\mathrm{b}}$ & $5.3 \pm 5.0^{\mathrm{d}}$ \\
\hline
\end{tabular}

Another unexpected effect of $\mathrm{Y}_{1}$ dispersal found in this study was the differentiated response to live traps by adult females in the three habitats (Table 3 ). These females were significantly more trappable on the island than in the open optimal habitat or in the suboptimal habitat. (Other age and sex groups did not show important interhabitat differences in trappability.) In fact, a highly significant correlation $(r=0.88, p<0.01)$ between crowding in the female territories and the female trappability was found for the three habitats.

This correlation may be interpreted as follows: pregnant and nursing females are highly sensitive to any deficiencies in their diet. When food present in the crowded territories of insular females becomes less nutritionally valuable they seek new sources of high-quality food and this increases the frequency of their visits to oats-baited traps. In the open optimal habitat (and even more so in the 
suboptimal one) their territories are less crowded and less food depleted. Hence, bait exposed in traps is less attractive and the trappability lower.

This account of events allows the conclusion that resident female relatives of $\mathrm{Y}_{1}$ dispersers benefit greatly from their emigration, which reduces local competition for resources. Time of dispersal may be viewed as optimal for residents since it gives most benefits to both, parent generation, which in June is still in top breeding condition, and to $\mathrm{Y}_{2}$ individuals which soon mature.

\section{Conclusions}

Data presnted here indicate that both, residents and dispersers may benefit from dispersal behaviour. The results are, therefore, inconclusive as far as the discrimination between the two hypotheses: $\mathrm{EFH}$ and $\mathrm{RFH}$, is concerned. Yet, they prove that, unlike Anderson (1989) claims, the two hypotheses are not mutually exclusive. The alternative of what is the ultimate factor governing the dispersal behaviour: genes of dispersers or genes/behaviour of their parents-residents, seems to be false. Dispersal behaviour may result from local interactions between family members, and due to gains in fitness to dispersers as well as to residents, may be viewed as a strategy increasing inclusive fitness of matrilines with dispersing young.

\section{References}

Anderson P. K. 1989. Dispersal in rodents: a resident fitness hypothesis. Spec. Publ. Amer. Soc. Mammal. 9: 1 - 139.

Cockburn A. 1988. Social behaviour in fluctuating populations. Croom Helm, London: 1-289.

Gaines M. S. and McClenaghan L. R. 1980. Dispersal in small mammals. Ann. Rev. Ecol. Syst. 11: $163-195$.

Gliwicz J. 1986. Dispersal in rodent populations - twenty years later. Wiad. Ekol. 32: 138 - 15. [In Polish with English summary]

Gliwicz J. 1988a. Seasonal dispersal in non-cyclic populations of Clethrionomys glareolus and Apodemus flavicollis. Acta theriol. 33: 263 - 272.

Gliwicz J. 1988b. The role of dispersal in models of small rodent population dymanics. Oikos 52: $219-221$.

Gliwicz J. 1989. Individuals and populations of the bank vole in optimal, suboptimal and insular habitats. J. Anim. Ecol. 58: 237 - 147.

Gliwicz J. 1990a. Habitat-dependent reproductive success in bank voles. [In: Social systems and population cycles in voles. R. H. Tamarin, R. S. Ostfeld, S. R. Pugh and G. Bujalska, eds]. Birkhauser Verlag, Basel: 169 - 179.

Gliwicz J. 1990b. The first born, their dispersal and vole cycles. Oecologia 83: $519-522$.

Gliwicz J. 1992. Patterns of dispersal in non-cyclic populations of small rodents. [In: Animal dispersal: small mammals as a model. N. C. Stenseth and W. Z. Lidicker, eds]. Chapman \& Hall, London: $147-159$.

Lidicker W. Z. 1975. The role of dispersal in the demography of small mammals. [In: Small mammals, their productivity and population dynamics. F. B. Golley, K. Petrusewicz and L. Ryszkowski, eds]. Cambridge Univ. Press 5: $103-128$. 
Stenseth N. C. 1983. Causes and consequences of dispersal in small mammals. [In: The ecology of animal movement. I. R. Swingland and P. J. Greenwood, eds]. Clarendon Press, Oxford: 63 - 101.

Stenseth N. C. and Lidicker W. Z. (eds) 1992. Animal dispersal: small mammals as a model. Chapman \& Hall, London: $1-240$.

Tamarin R. H. 1978. Dispersal, population regulation and K-selection in field mice. Amer. Natur. 112: $545-555$.

Received 2 June 1991, revised 15 March 1993, accepted 16 March 1993. 